\title{
Kajian Inflow, Outflow Dan Water Balance Danau Beratan Di Dataran Tinggi Bedugul Bali
}

\section{Dewa Made Atmaja}

Masuk: 10042019 / Diterima: 11062019 / Dipublikasi: 30062019 (C) 2019 Fakultas Hukum dan IImu Sosial UNDIKSHA dan IGI

\begin{abstract}
Knowledge of water balance is a component that cannot be separated, among others: inflow, outflow, and heap of water. The research aims to: 1) find out the inflow variation (rainfall, runoff), 2) find out the variety of outflow flow (evaporation, water use), 3) find out the water balance that occurs in Lake Beratan. The object of this research is the quantity of Lake Beratan water; data collection methods used are observation methods, interview methods, and documentation study methods. Data analysis in this study all used quantitative descriptive methods. The results of this study indicate that the variation of Lake Beratan inflow at the lowest monthly average for five years is in September of $3.18 \times 106 \mathrm{m3}$ and the highest monthly percentage is in January at $269.63 \times 106 \mathrm{m3}$. The average annual inflow is $107.50 \times 106 \mathrm{m3}$. The variation of inflow is caused by land cover vegetation, topography, and slope. Lake Beratan outflow variations the lowest monthly average for five years in November at $27.3 \times 106 \mathrm{m3}$ and the highest monthly average is in March at $27.4 \times 106$ m3. The average annual outflow is $328.32 \times 106$ m3. The water balance for the period 2013-2017 has a monthly inflow value higher than flow, which is equal to $961.64 \times 106 \mathrm{m3}$ or with an average balance of $80.14 \times 106 \mathrm{~m} 3$ per month. Based on the analysis of changes in water deposits for five years from 2013-2017, the highest monthly water balance was found in January and December at $312.22 \times 106 \mathrm{m3}$ (positive), while the lowest in August was -24, $14 \times 106 \mathrm{m3}$ (negative).
\end{abstract}

\section{Key words: Inflow; Outflow; Water Balance}

\begin{abstract}
Abstrak Pengetahuan tentang imbangan air merupakan suatu komponen yang tidak dapat dipisahkan antara lain: pengaliran masuk (inflow), pengaliran keluar (outflow), dan timbunan air. Penelitian bertujuan untuk: 1) mengetahui variasi inflow (curah hujan, limpasan), 2) mengetahui variasi aliran outflow (evaporasi, pemakaian air), 3) mengetahui water balance yang terjadi di Danau Beratan. Objek penelitian ini adalah kuantitas air Danau Beratan, metode pengumpulan data yang digunakan adalah metode observasi, metode interview/wawancara, dan metode studi dokumentasi. Analisis data dalam penelitian ini seluruhnya menggunakan metode deskriptif kuantitatif. Hasil penelitian ini menunjukan bahwa, variasi pengaliran masuk (inflow) Danau Beratan rata-rata bulanan terendah selama 5 tahun terdapat pada bulan September sebesar 3,18 x $106 \mathrm{~m} 3$ dan rata-rata bulanan tertinggi terdapat pada bulan Januari sebesar 269,63 x $106 \mathrm{m3}$. Besar pengaliran masuk (inflow) tahunan rata-rata sebesar $107,50 \times 106 \mathrm{~m} 3$. Adanya variasi pengaliran masuk (inflow) tersebut disebabkan oleh faktor vegetasi penutup lahan (land cover vegetation); topografi serta kemiringan lereng. Variasi pengaliran keluar (outflow) Danau Beratan rata-rata bulanan terendah selama 5 tahun terdapat November sebesar $27,3 \times 106 \mathrm{~m} 3$ dan rata-rata bulan tertinggi terdapat pada bulan Maret sebesar 27,4 × $106 \mathrm{m3}$. Pengaliran ke luar (outflow) tahunan rata-rata sebesar 328,32 x 106 m3. Imbangan air periode tahun 2013-2017 memiliki nilai pengaliran masuk (inflow) bulanan lebih besar daripada pengaliran ke luar (outflow), yaitu sebesar 961,64 x $106 \mathrm{~m} 3$ atau dengan imbangan rata-rata tiap bulannya sebesar 80,14 × $106 \mathrm{m3}$. Berdasarkan analisa debit perubahan timbunan air selama 5 tahun dari tahun 2013-2017, menunjukan rata-rata imbangan air bulanan tertinggi terdapat pada bulan Januari dan Desember sebesar 312,22 x $106 \mathrm{m3}$ (positif), sedangkan terendah terdapat pada bulan Agustus sebesar -24,14 × $106 \mathrm{m3}$ (negatif).
\end{abstract}

Kata kunci : Pengaliran Masuk; Pengaliran Keluar; Imbangan Air

\section{Pendahuluan}

Sumber air danau yang berasal dari air hujan akan melalui suatu sistem

Dewa Made Atmaja

Prodi Survei dan Pemetaan, Undiksha Singaraja atmajadewamade@yahoo.com yang berantai yang disebut siklus hidrologi. Air hujan yang jatuh di permukaan bumi akan menjadi aliran permukaan (surface run off), kemudian meresap kedalam tanah menjadi aliran bawah tanah, hal itu terjadi melalui proses 
infiltrasi dan perkolasi. Selebihnya akan terkumpul di dalam jaringan alur sungai sebagai aliran sungai (river flow). Apabila kondisi tanah memungkinkan, sebagian air tanah infiltrasi akan mengalir kembali ke sungai, atau genangan lainnya seperti waduk dan danau. Sebagian lainnya muncul kembali kepermukaan tanah sebagai mata air. Mata air tersebut dapat terkumpul lagi kedalam alur sungai atau langsung menuju laut (Soewarno, 2000:4)

Air merupakan salah satu sumber daya alam yang menjadi kebutuhan pokok bagi berlangsungnya kehidupan semua mahluk hidup. Meningkatnya populasi dan kegiatan mahluk hidup, terutama manusia menyebabkan meningkatnya kebutuhan air. Sementara itu, perubahan lingkungan yang ditimbulkan oleh kegiatan manusia, menyebabkan perubahan pada karakter hidrologi yang pada akhirnya telah mengakibatkan penurunan kapasitas persediaan air dari daerah yang bersangkutan. Oleh karena itu perlu dijaga suatu kondisi, minimal terjadi keseimbangan antara kebutuhan dan ketersediaan air.

Danau Beratan yang terletak di Kabupaten Tabanan adalah danau terluas ketiga di Pulau Bali. Danau yang terletak di kawasan kaldera Gunung Beratan tersebut merupakan danau vulkanis yang mempunyai luas $3,764 \mathrm{~km} 2$. Volume air secara keseluruhan adalah 62,58 x 106 m3, sedangkan kedalaman rata-ratanya mencapai 12,74 m. Luas daerah tangkapan air mencapai 13,49 km2. Daerah tangkapan air ini mempunyai fungsi penting bagi masyarakat di sekitar danau yang memiliki wilayah yang cukup kering dan sulit untuk mendapatkan air bersih (Tabanan dalam Angka, 2018).
Pengetahuan tentang imbangan air merupakan suatu komponen yang tidak dapat dipisahkan antara lain: pengaliran masuk (inflow), pengaliran keluar (outflow), dan timbunan air. Pengaliran masuk (inflow) merupakan sejumlah yang masuk ke dalam suatu struktur tertentu (misalnya daerah aliran sungai, danau, kolam tanah, serta akuifer) yang kemudian melalui satu atau beberapa proses tertentu dalam struktur tersebut akan ke luar sejumlah air yang disebut sebagai pengaliran ke luar (outflow). Dengan pengertian tersebut, Warren Viessmen (1972:20), merumuskannya kedalam suatu konsep yang disebut sebagai Konsep Imbangan Air (Water Balance Concept). Berdasarkan konsep ini, jumlah pengaliran masuk dan jumlah pengaliran ke luar yang terjadi pada periode waktu tertentu di daerah aliran sungai merupakan imbangan di daerah itu.

Berdasarkan pengetahuan tentang imbangan air di daerah penelitian, yaitu Daerah Danau Beratan, maka akan dapat diketahui gambaran potensial air di suatu danau, asal airnya, perubahan simpanan airnya, persebaran air yang terjadi dan jumlah air yang hilang (water losses) dari daerah tersebut dari waktu ke waktu. Sesuai dengan latar belakang didapat suatu masalah pokok yaitu studi imbangan air di Danau Beratan.

Namun untuk memperoleh hasil penelitian yang lebih sistematis maka perlu diuraikan dalam tujuan penelitian berikut, yaitu analisis pengaliran masuk (curah hujan, limpasan) di Danau Beratan, analisis pengaliran keluar (evaporasi dan pemakaian air) di Danau Beratan dan kajian imbangan air yang terjadi di Danau Beratan. 


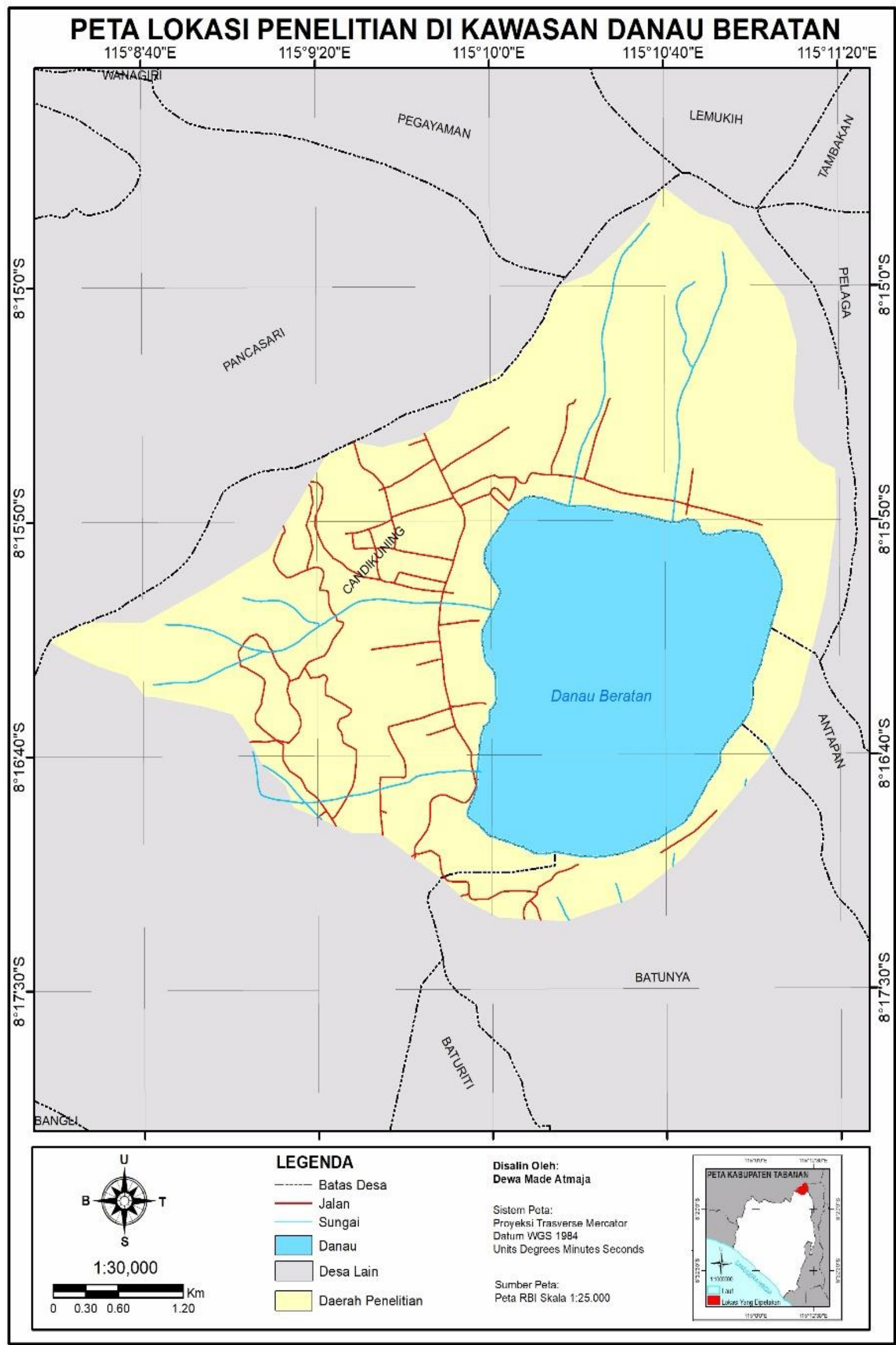

Gambar 3. Kawasan Danau Beratan 


\section{Metode}

Objek penelitian ini adalah kuantitas air Danau Beratan, metode pengumpulan data yang digunakan adalah metode observasi, metode interview/wawancara, dan metode studi dokumentasi. Analisis data dalam penelitian ini seluruhnya menggunakan metode deskriptif kuantitatif.

\section{Hasil dan Pembahasan}

\subsection{Variasi Inflow, Outflow dan Water Balance}

Hasil perhitungan pengaliran masuk (inflow), pengaliran keluar (outflow), dan timbunan air seperti terlihat pada tabel-tabel perhitungan data berikut ini.

Tabel 1. Debit Curah Hujan Rata-rata dari Tahun 2013 - 2017 dalam ( $\mathrm{m}^{3} /$ detik)

\begin{tabular}{|c|c|c|c|c|c|c|}
\hline \multirow{2}{*}{ Bulan } & \multicolumn{5}{|c|}{ Tahun } & \multirow{2}{*}{ Mean } \\
\cline { 2 - 6 } & 2013 & 2014 & 2015 & 2016 & 2017 & \\
\hline Januari & 10.33 & 113.99 & 91.61 & 55.42 & 76.05 & 69.48 \\
\hline Februari & 22.53 & 73.39 & 94.74 & 170.46 & 76.30 & 87.48 \\
\hline Maret & 51.69 & 66.98 & 90.43 & 80.14 & 27.18 & 63.28 \\
\hline April & 22.92 & 28.67 & 34.45 & 21.72 & 11.02 & 23.76 \\
\hline Mei & 0.23 & 27.53 & 0.73 & 1.41 & 11.53 & 8.29 \\
\hline Juni & 1.77 & 4.83 & 3.25 & 11.54 & 3.16 & 4.91 \\
\hline Juli & 1.09 & 3.68 & 1.09 & 0.22 & 0.25 & 1.27 \\
\hline Agustus & 0.58 & 0.24 & 0.11 & 6.09 & 0.24 & 1.45 \\
\hline September & 0.05 & 2.04 & 0.24 & 0.25 & 1.35 & 0.79 \\
\hline Oktober & 9.363 & 2.89 & 1.29 & 15.77 & 1.59 & 6.18 \\
\hline Nopember & 27.90 & 4.47 & 4.07 & 62.64 & 12.12 & 22.24 \\
\hline Desember & 46.03 & 59.43 & 19.16 & 67.04 & 27.56 & 43.84 \\
\hline Jumlah & 194.48 & 388.14 & 341.17 & 492.7 & 248.35 & 263.49 \\
\hline Rerata & 16,21 & 32,35 & 28,43 & 41,06 & 20,69 & 27,75 \\
\hline
\end{tabular}

Sumber: Data Primer, 2018

Tabel 2. Debit Evapotranspirasi Potensial ( $\mathrm{m}^{3} /$ detik) dari Tahun 2013-2017

\begin{tabular}{|c|c|c|c|c|c|c|}
\hline \multirow{2}{*}{ Bulan } & \multicolumn{5}{|c|}{ Tahun } & \multirow{2}{*}{ Mean } \\
\cline { 2 - 6 } & 2013 & 2014 & 2015 & 2016 & 2017 & \\
\hline Januari & 2.13 & 1.734 & 1.782 & 1.584 & 1.014 & 1.6488 \\
\hline Februari & 2.238 & 1.83 & 1.908 & 1.578 & 1.086 & 1.728 \\
\hline Maret & 2.328 & 1.956 & 2.028 & 1.602 & 1.176 & 1.818 \\
\hline April & 2.37 & 1.986 & 1.974 & 1.554 & 1.278 & 1.8324 \\
\hline Mei & 2.292 & 1.902 & 1.92 & 1.446 & 1.224 & 1.7568 \\
\hline Juni & 2.232 & 1.794 & 1.854 & 1.326 & 1.158 & 1.6728 \\
\hline Juli & 2.178 & 1.74 & 1.782 & 1.218 & 1.086 & 1.6008 \\
\hline Agustus & 2.118 & 1.65 & 2.106 & 1.122 & 0.99 & 1.5972 \\
\hline September & 2.058 & 1.572 & 1.59 & 1.038 & 0.936 & 1.4388 \\
\hline Oktober & 1.986 & 1.476 & 1.476 & 0.972 & 0.792 & 1.3404 \\
\hline Nopember & 1.89 & 1.476 & 1.416 & 0.918 & 0.942 & 1.3284 \\
\hline Desember & 1.872 & 1.464 & 1.494 & 0.942 & 1.086 & 1.3716 \\
\hline Mean & 2.141 & 1.715 & 1.7775 & 1.275 & 1.064 & 1.5945 \\
\hline
\end{tabular}

Sumber: Data Primer, 2018 
Tabel 3. Debit Limpasan (Q) dari Tahun 2013-2017 (m³/dtk)

\begin{tabular}{|c|c|c|c|c|c|c|}
\hline \multirow{2}{*}{ Bulan } & \multicolumn{5}{|c|}{ Tahun } & \multirow{2}{*}{ Mean } \\
\cline { 2 - 6 } & 2013 & 2014 & 2015 & 2016 & 2017 & \\
\hline Januari & 4.92 & 56.79 & 45.59 & 27.52 & 37.90 & 34.54 \\
\hline Februari & 11.01 & 36.48 & 47.15 & 85.04 & 38.01 & 43.54 \\
\hline Maret & 25.58 & 33.26 & 44.98 & 39.88 & 13.45 & 31.43 \\
\hline April & 11.20 & 14.10 & 17.00 & 10.67 & 5.35 & 11.66 \\
\hline Mei & 0.46 & 13.54 & 0.14 & 0.53 & 5.61 & 4.06 \\
\hline Juni & 0.63 & 2.20 & 1.41 & 5.60 & 1.44 & 2.26 \\
\hline Juli & 0.30 & 1.63 & 0.34 & 0.01 & 0.00 & 0.46 \\
\hline Agustus & 0.05 & 0.05 & 0.40 & 2.91 & 0.00 & 0.68 \\
\hline September & 0.67 & 0.83 & 0.16 & 0.00 & 0.55 & 0.44 \\
\hline Oktober & 4.45 & 1.26 & 0.47 & 7.76 & 0.69 & 2.93 \\
\hline Nopember & 13.73 & 2.06 & 1.86 & 31.21 & 5.94 & 10.96 \\
\hline Desember & 22.79 & 29.54 & 9.40 & 33.40 & 13.64 & 21.75 \\
\hline Mean & 7.98 & 15.98 & 14.08 & 20.38 & 10.22 & 13.73 \\
\hline
\end{tabular}

Sumber: Data Primer, 2018

Tabel 4. Debit Pengaliran Masuk (Inflow) dari Tahun 2013-2017 dalam $\left(10^{6} \mathrm{~m}^{3}\right)$

\begin{tabular}{|c|c|c|c|c|c|c|}
\hline \multirow{2}{*}{ Bulan } & \multicolumn{5}{|c|}{ Tahun } & \multirow{2}{*}{ Mean } \\
\cline { 2 - 6 } & 2013 & 2014 & 2015 & 2016 & 2017 & \\
\hline Januari & 39.53 & 442.66 & 355.62 & 214.98 & 295.36 & 269.63 \\
\hline Februari & 86.94 & 284.78 & 367.78 & 662.26 & 296.29 & 339.61 \\
\hline Maret & 200.28 & 259.82 & 350.98 & 311.09 & 105.31 & 245.50 \\
\hline April & 88.44 & 110.86 & 133.36 & 83.95 & 42.43 & 91.81 \\
\hline Mei & 1.79 & 106.45 & 2.26 & 5.03 & 44.43 & 31.99 \\
\hline Juni & 6.22 & 18.22 & 12.08 & 44.43 & 11.92 & 18.57 \\
\hline Juli & 3.60 & 13.76 & 3.71 & 0.60 & 0.65 & 4.46 \\
\hline Agustus & 1.63 & 0.75 & 1.32 & 23.33 & 0.62 & 5.53 \\
\hline September & 1.87 & 7.44 & 1.04 & 0.65 & 4.92 & 3.18 \\
\hline Oktober & 35.80 & 10.76 & 4.56 & 60.99 & 5.91 & 23.60 \\
\hline Nopember & 107.90 & 16.93 & 15.37 & 243.26 & 46.81 & 86.05 \\
\hline Desember & 178.38 & 230.61 & 74.03 & 260.34 & 106.79 & 170.03 \\
\hline Mean & 62.70 & 125.25 & 110.18 & 159.24 & 80.12 & 107.50 \\
\hline
\end{tabular}

Sumber: Data Primer, 2018

Tabel 5. Debit Evaporasi (Q) dari Tahun 2013-2017 Dalam ( $\mathrm{m}^{3} /$ detik)

\begin{tabular}{|c|c|c|c|c|c|c|}
\hline \multirow{2}{*}{ Bulan } & \multicolumn{5}{|c|}{ Tahun } & \multirow{2}{*}{ Mean } \\
\cline { 2 - 5 } & 2013 & 2014 & 2015 & 2016 & 2017 & \\
\hline Januari & 0.19 & 0.15 & 0.16 & 0.14 & 0.09 & 0.146 \\
\hline Februari & 0.19 & 0.16 & 0.17 & 0.14 & 0.10 & 0.152 \\
\hline Maret & 0.20 & 0.17 & 0.18 & 0.14 & 0.11 & 0.16 \\
\hline April & 0.20 & 0.17 & 0.17 & 0.14 & 0.11 & 0.158 \\
\hline Mei & 0.20 & 0.17 & 0.17 & 0.13 & 0.11 & 0.156 \\
\hline Juni & 0.19 & 0.16 & 0.16 & 0.12 & 0.10 & 0.146 \\
\hline Juli & 0.19 & 0.15 & 0.16 & 0.11 & 0.09 & 0.14 \\
\hline Agustus & 0.18 & 0.14 & 0.18 & 0.10 & 0.09 & 0.138 \\
\hline September & 0.18 & 0.13 & 0.14 & 0.09 & 0.08 & 0.124 \\
\hline Oktober & 0.17 & 0.13 & 0.13 & 0.09 & 0.07 & 0.118 \\
\hline Nopember & 0.16 & 0.13 & 0.13 & 0.08 & 0.08 & 0.116 \\
\hline Desember & 0.16 & 0.13 & 0.13 & 0.08 & 0.09 & 0.118 \\
\hline Mean & 0.184167 & 0.149167 & 0.156667 & 0.113333 & 0.093333 & 0.139333 \\
\hline
\end{tabular}

Sumber: Data Primer, 2018 
Tabel 6. Pemakaian/kebutuhan Air Non Irigasi Hasil Olahan ( $\mathrm{m}^{3} /$ detik) Rata-rata 5 Tahun (2013-2017)

\begin{tabular}{|c|c|c|c|c|}
\hline \multirow{2}{*}{ Daerah Aliran/Pemakai } & \multicolumn{3}{|c|}{ Jenis Pemakaian } & \multirow{2}{*}{ Jumlah } \\
\cline { 2 - 4 } & Domestik & Industri & Pariwisata & \\
\hline Dusun Kembangmerta & 0.053 & 0.009 & 0.015 & 0.024 \\
\hline Dusun Candikuning 1 & 0.117 & 0.016 & 0.028 & 0.161 \\
\hline Dusun Candikuning 2 & 0.037 & 0.005 & 0.009 & 0.051 \\
\hline Dusun Bukit Catu & 0.041 & 0.006 & 0.010 & 0.057 \\
\hline Dusun Taman Tanda & 0.042 & 0.011 & 0.001 & 0.054 \\
\hline JUMLAH & 0.237 & 0.047 & 0.063 & 0.347 \\
\hline
\end{tabular}

Sumber: Data Primer, 2018

Tabel 7. Debit Pengaliran Ke Luar (outflow) Tahun 2013-2017 dalam ( $\mathrm{m}^{3} /$ detik).

\begin{tabular}{|c|c|c|c|c|c|c|}
\hline \multirow{2}{*}{ Bulan } & \multicolumn{5}{|c|}{ Tahun } & \multirow{2}{*}{ Mean } \\
\cline { 2 - 6 } & 2013 & 2014 & 2015 & 2016 & 2017 & \\
\hline Januari & 27.49 & 27.39 & 27.41 & 27.36 & 27.23 & 27.376 \\
\hline Februari & 27.49 & 27.41 & 27.44 & 27.36 & 27.26 & 27.392 \\
\hline Maret & 27.52 & 27.44 & 27.47 & 27.36 & 27.28 & 27.414 \\
\hline April & 27.52 & 27.44 & 27.44 & 27.36 & 27.28 & 27.408 \\
\hline Mei & 27.52 & 27.44 & 27.44 & 27.34 & 27.28 & 27.404 \\
\hline Juni & 27.49 & 27.41 & 27.41 & 27.31 & 27.26 & 27.376 \\
\hline Juli & 27.49 & 27.39 & 27.41 & 27.28 & 27.23 & 27.36 \\
\hline Agustus & 27.47 & 27.36 & 27.47 & 27.26 & 27.23 & 27.358 \\
\hline September & 27.47 & 27.34 & 27.36 & 27.23 & 27.21 & 27.322 \\
\hline Oktober & 27.44 & 27.34 & 27.34 & 27.23 & 27.18 & 27.306 \\
\hline Nopember & 27.41 & 27.34 & 27.34 & 27.20 & 27.21 & 27.3 \\
\hline Desember & 27.41 & 27.34 & 27.34 & 27.20 & 27.23 & 27.304 \\
\hline Jumlah & 329.72 & 328.64 & 328.87 & 327.49 & 326.88 & 328.32 \\
\hline
\end{tabular}

Sumber: Data Primer, 2018

Tabel 8. Perubahan Timbunan Air $(\Delta S)$ Rata-rata Tahunan 2013-2017 dalam $\left(10^{6} \mathrm{~m}^{3}\right)$

\begin{tabular}{|c|c|c|c|}
\hline Tahun & $\begin{array}{c}\text { Inflow } \\
\left(10^{6} \mathrm{~m}^{3}\right)\end{array}$ & $\begin{array}{c}\text { Outflow } \\
\left(10^{6} \mathrm{~m}^{3}\right)\end{array}$ & $\begin{array}{c}(\Delta \mathrm{S}) \\
\left(10^{6} \mathrm{~m}^{3}\right)\end{array}$ \\
\hline 2013 & 712.85 & 329.70 & 383.15 \\
\hline 2014 & 1503.04 & 328.25 & 1174.79 \\
\hline 2015 & 1322.11 & 328.85 & 993.26 \\
\hline 2016 & 1910.91 & 327.51 & 1583.4 \\
\hline 2017 & 961.44 & 326.88 & 634.56 \\
\hline Jumlah & 6410.35 & 1641.19 & 4769.16 \\
\hline Rata-rata & 1282.07 & 328.238 & 953.832 \\
\hline
\end{tabular}

Sumber: Data Primer, 2018

\subsection{Variasi Pengaliran Masuk}

Pengaliran masuk (inflow) terdiri atas beberapa komponen, antara lain curah hujan rata-rata daerah $(P)$ melalui perhitungan metode Polygon Thienssen; dan limpasan (Ro) melalui perhitungan metode Thornthwaite-Mather. Kedua komponen tersebut memiliki pengaruh pada pengaliran masuk yang berbeda untuk tiap-tiap daerah sesuai dengan karakteristik geografisnya, seperti faktor kelerengan/topografis,

geologi, geomorfologi, penggunaan lahan, iklim, erosi, tanah, hidrologi, dan vegetasi (Atmaja et al. 2018).

Hujan merupakan air yang jatuh ke permukaan bumi, dan mempengaruhi besar dari pengaliran masuk danau. Curah hujan daerah yang diperoleh melalui perhitungan metode Polygon Thienssen menggunakan data curah hujan dari 4 stasiun penakar hujan 
terdekat dengan Danau Beratan. Dengan demikian, keberadaan stasiun penakar hujan memiliki peranan serta hubungan dalam mempresentasikan jumlah debit atau aliran masuk yang berasal dari curah hujan melalui pengukuran oleh alat penakar hujan serta diharapkan mampu menampilkan variasi debit yang dipengaruhi pula oleh keadaan fisiografi tiap-tiap titik stasiun.

Selanjutnya untuk melihat variasi curah hujan rata-rata bulanan dan tahunan berdasarkan perhitungan. Berdasarkan hasil perhitungan curah hujan dengan metode Polygon Thienssen, maka diperoleh variasi curah hujan ratarata daerah Danau Beratan tertinggi terdapat Februari yaitu sebesar 87,48 m3/detik. Sedangkan curah hujan ratarata terendah terdapat pada bulan September yaitu sebesar $0,79 \mathrm{~m} 3 /$ detik dengan rata-rata tiap bulannya selama 5 tahun (2013-2017) adalah sebesar 27,75 m3/detik.

Perbedaan curah hujan pada tiap bulan yang ada disebabkan oleh faktor iklim yang ada di Indonesia pada umumnya. Karena kecendrungan di Indonesia mengalami 2 (dua) musim yaitu musim hujan dan musim kemarau. Tingginya curah hujan pada bulan Februari disebabkan bertepatan pada musim penghujan dan begitu pula sebaliknya pada bulan September.

Limpasan sungai dipengaruhi oleh lereng danau, tekstur tanah, kandungan air dalam tanah, tingkat kekasaran permukaan tanah dan vegetasi. Untuk perhitungan limpasan Danau Beratan membutuhkan curah hujan bulanan, evapotranspirasi potensial, WHC daerah penelitian, serta tabel-tabel dari Thornthwaite-Mather. Berikut disajikan variasi limpasan Danau Beratan selama 5 tahun (2013-2017).

Berdasarkan hasil perhitungan, diperoleh debit total limpasan tahunan tertinggi terdapat pada bulan Februari yaitu sebesar 43,54 m3/detik. Debit terendah terdapat pada bulan September yaitu sebesar $0,44 \mathrm{~m} 3 /$ detik dengan ratarata sebesar 10,85 m3/detik. Oleh karena faktor kelerengan daerah penelitian sebagian terkategori curam maka limpasan yang masuk ke dalam danau terkategori cepat.

Oleh karena nilai limpasan hasil perhitungan tersebut merupakan nilai limpasan Danau Beratan secara keseluruhan dalam kurun waktu 5 tahun (2013-2017), maka variasi limpasan juga akan diuraikan berupa faktor-faktor fisik yang mempengaruhi komponen meteorologis dan laju limpasan. Diantaranya adalah sebagai berikut.

1) Faktor meteorologis seperti presipitasi, diketahui bahwa curah hujan rata-rata tertinggi berdasarkan perhitungan Poligon Thienssen pada bulan Februari, kemudian air yang jatuh ke sungai tersebut separuhnya akan menjadi limpasan pada bulan berikutnya.

2) Faktor-faktor meteorologi seperti radiasi matahari, suhu, kelembaban, kecepatan angin, tekanan angin, tekanan atmosfer, yang mempengruhi limpasan. Nilai Evapotranspirasi Potensial pada bulan-bulan September-Desember yang dibawah rata-rata menunjukan adanya limpasan yang tinggi bila dibandingkan bulan-bulan berikutnya. Nilai Evapotranspirasi potensial pada penelitian ini hanya dapat diperoleh dari hasil perhitungan dengan mengalikan koefisien yang telah tersedia (berkisar 0,60-0,85) dengan evaporasi air bebas.

3) Faktor topografi danau yang relatif bervariasi dan kemiringan lereng cukup memberikan kontribusi terhadap cepat lambatnya kecepatan aliran atas permukaan lahan (overland flow) Danau Beratan. 
4) Adanya vegetasi yang cukup lebat terutama di pinggir danau yaitu hutan sebagai pemasok air, serta penggunaan lahan (land use) berpengaruh terhadap nilai Water Holding Capacity (WHC) sebagai penentu cepatnya limpasan untuk Danau Beratan.

5) Bentuk daerah tangkapan daerah Danau Beratan yang agak memanjang tetapi luas, sehingga memungkinkan dimasukan seluruhnya dalam daerah intensitas curah hujan maksimum dari hujanhujan lokal, dan waktu yang diperlukan bagi aliran permukaan akan menjadi lebih besar. Karena, laju limpasan berkurang dengan semakin melebarnya daerah aliran.

Dengan demikian, berdasarkan hasil perhitungan rerata, maka diperoleh pengaliran masuk rata-rata bulanan terendah selama 5 tahun terdapat pada bulan September sebesar 3,18 x 106 m3 dan rata-rata bulan tertinggi terdapat pada bulan Januari sebesar 269,63 x 106 m3. Besar pengaliran masuk (inflow) tahunan rata-rata sebesar 107,50 x $106 \mathrm{~m}$.

Terjadinya pengaliran masuk terendah pada bulan September disebabkan oleh faktor curah hujan pada bulan bersangkutan yang cenderung rendah yang juga berpengaruh langsung terhadap limpasan yang terjadi pada bulan bersangkutan. Hal ini akan berbeda pada bulan-bulan awal musin hujan misalnya Januari yang curah hujannya cenderung tinggi. Hal ini sesuai hasil penelitian yang dilakukan oleh Atmaja pada tahun 2004 di Danau Beratan.

\subsection{Variasi Pengaliran Ke Luar (outflow)}

Pengaliran keluar terdiri dari Debit Evaporasi, pemakaian air untuk irigasi, dan pemakaian air untuk non irigasi. Variasi pengaliran ke luar (outflow) dalam hal ini diuraikan sesuai dengan karakteristik daerah serta aspek pemanfaatannya.

Nilai evaporasi daerah penelitian dalam hal ini didapat dengan menggunakan perhitungan yang intinya mengalikan antara luas bidang dengan tebal muka depan air dan dibagi dengan jumlah detik dalam satu bulan, sehingga hasil yang di dapat dalam satuan (m3/detik). Dapat dilihat besarnya evaporasi tersebar merata setiap bulan dengan besarnya evaporasi potensial rata-rata sebesar $0,139 \mathrm{~m} 3 /$ detik.

Evaporasi sangat dipengaruhi oleh besarnya penyinaran matahari. Pada daerah penelitian sinar matahari sangat merata pada semua daerah sehingga memungkinkan terjadinya evaporasi (penguapan) yang juga merata pada semua daerah (Atmaja et al. 2017).

Irigasi merupakan bentuk penyediaan, pembagian pemberian, dan pengguanaan air untuk pertanian dengan menggunakan satu kesatuan saluran dan bangunan berupa jaringan irigasi. Sebagai pengguna air dalam sektor pertanian, irigasi melakukan pemanfaatan air paling besar di Bali, terutama dari air permukaan khususnya danau.

Berdasarkan

data pemakaian/kebutuhan air untuk irigasi, terlihat jelas bahwa jumlah kebutuhan air untuk irigasi yang meningkat besar pada awal mula pola tanam dalam periode tersebut. Berdasarkan perhitungan pemekaian air di daerah Danau Beratan, dapat di peroleh keterangan bahwa ratarata kebutuhan air irigasi sebesar 10,07 m3/detik.

Penggunaan air untuk non irigasi terdiri dari kebutuhan domestik (seharihari), industri, dan pariwisata. Penduduk merupakan konsumen penting yang harus mendapatkan prioritas dalam pemenuhan pelayanannya. Karena kesejahteraan penduduklah yang pada akhirnya menjadi parameter keberhasilan pembangunan pada suatu daerah. Berdasarkan hasil 
perhitungan, diperoleh besarnya pemakaian/kebutuhan air hasil olahan rata-rata dalam kurun waktu 5 tahun (2013-2017) untuk jenis pemakaian domestik, industri, dan pariwisata adalah sebesar 0,347 m3/detik. Hampir semua daerah penelitian pemakaian non irigasi paling besar digunakan untuk kebutuhan domestik kemudian diikuti oleh pemakaian untuk pariwisata dan industri.

Dengan demikian berdasarkan hasil perhitungan, maka diperoleh variasi pengaliran ke luar dengan nilai rata-rata bulanan terendah selama 5 tahun terdapat pada bulan November sebesar 27,3 x 106 m3, bulan tertinggi pada bulan Maret sebesar 27,414 x $106 \mathrm{~m} 3$ dengan pengaliran ke luar (outflow) tahunan ratarata sebesar 328,32 x 106 m3.

Besarnya pengaliran keluar yang terjadi sangat dipengaruhi oleh evaporasi dan pemakaian air baik irigasi maupun non irigasi. Untuk daerah penelitian pemakaian air lebih dominan mempengaruhi pengaliran keluar. Hal ini disebabkan oleh faktor pertanian yang memperhitungkan bulan-bulan penghujan serta pemakaian air non irigasi yang terus meningkat. Hal ini sejalan dengan penelitian yang serupa yang dilakukan di DAS Ayung oleh Yudi Wisnawa pada tahun 2005.

\subsection{Variasi Imbangan Daerah Danau Batur}

Dari hasil imbangan air $(\Delta S)$ periode tahun 2013-2017 memiliki nilai pengaliran masuk (inflow) bulanan lebih besar daripada pengaliran keluar (outflow), yaitu sebesar 961,64 x 106 m3 atau dengan imbangan rata-rata tiap bulannya sebesar 80,14 x $106 \mathrm{m3}$.

Nilai perubahan timbunan dapat bernilai positif dan negatif, nilai positif apabila volume suatu waktu lebih kecil dari volume berikutnya, sedangkan perubahan timbunan air bernilai negative apabila volume suatu waktu lebih besar dari volume berikutnya. Berdasarkan analisa debit perubahan timbunan air selama 5 tahun dari tahun 2013-2017, menunjukan rata-rata imbangan air bulanan tertinggi terdapat pada bulan Januari dan Desember sebesar 312,22 x $106 \mathrm{~m} 3$ (positif), sedangkan terendah terdapat pada bulan Agustus sebesar 24,14 x $106 \mathrm{m3}$ (negatif).

Adanya variasi imbangan air baik secara bulanan maupun tahunan, disebabkan oleh perbedaan faktor pengaliran masuk (inflow) dan pengaliran keluar (outflow) Danau Batur itu sendiri, disamping itu faktor fisik daerah turut pula mempengaruhi terjadinya variasi tersebut. Besarnya jumlah curah hujan daerah dan limpasan air permukaan di danau, serta tingkat pemakaian air yang masih normal, mampu menjadikan Danau Beratan memiliki imbangan air yang bernilai surplus serta mampu mencukupi kebutuhan air di daerah tersebut.

\section{Kesimpulan}

Berdasarkan Berdasarkan paparan hasil penelitian dan pembahasan yang telah disajikan di atas, maka dapat ditarik kesimpulan sebagai berikut. Pertama, variasi pengaliran masuk (inflow) Danau Beratan rata bulanan terendah selama 5 tahun terdapat pada pada bulan September sebesar 3,18 x $106 \mathrm{~m} 3$ dan rata-rata bulan tertinggi terdapat pada bulan Januari sebesar 269,63 x 106 m3. Besar pengaliran masuk (inflow) tahunan rata-rata sebesar 107,50 x 106 m3. Adanya variasi pengaliran masuk (inflow) tiap segmen tersebut disebabkan oleh faktor vegetasi penutup lahan (land cover vegetation); topografi serta kemiringan lereng. Kedua, variasi pengaliran ke luar (outflow) Danau Beratan rata-rata bulanan terendah selama 5 tahun terdapat bulan November sebesar 27,3 x 106 m3 dan rata-rata bulan tertinggi terdapat pada bulan Maret sebesar 27,3 x 106 m3. Pengaliran ke luar (outflow) tahunan rata- 
rata daerah sebesar 328,32 x $106 \mathrm{~m} 3$. Ketiga, imbangan air $(\Delta S)$ periode tahun 2005-2009 memiliki nilai pengaliran masuk (inflow) bulanan lebih besar daripada pengaliran keluar (outflow), yaitu sebesar $961,64 \times 106 \mathrm{~m} 3$ atau dengan imbangan rata-rata tiap bulannya sebesar $80,14 \mathrm{x}$ 106 m3. Berdasarkan analisa debit perubahan timbunan air selama 5 tahun dari tahun 2013-2017, menunjukan ratarata imbangan air bulanan tertinggi terdapat pada bulan Januari dan Desember sebesar 312,22 x $106 \mathrm{~m} 3$ (positif), sedangkan terendah terdapat pada bulan Agustus sebesar - 24,14 x $106 \mathrm{~m} 3$ (negatif). Adanya variasi imbangan air baik secara bulanan maupun tahunan pada daerah penelitian, disebabkan oleh perbedaan faktor pengaliran masuk (inflow) dan pengaliran ke luar (outflow).

\section{Daftar Pustaka}

Atmaja Dewa Made. 2004. Kajian Imbangan Air Danau Buyan di Kecamatan Sukasada Kabupaten Buleleng. Laporan penelitian (tidak dipublikasikan). IKIP Negeri Singaraja.

Atmaja Dewa Made. Sri Budiastuti.
Prabang S. Sunarto. 2017. Sediment Characteristics and Benthos Community Spread in Lake Beratan in Bali. Proceding Advances in Social Science, Education and Humanities Research, volume 79, pp. 76-80. 1st International Conference on Geography and Education (ICGE 2016). Atlantis Press.

Atmaja Dewa Made. Sri Budiastuti. Prabang S. Sunarto. 2018. An ecohydrological-based

management of Lake Beratan in Bedugul, Bali. IOP Conf. Series: Earth and Environmental Science 148 (2018) $012024 . \quad$ doi $: 10.1088 / 1755-$ 1315/148/1/012024.

Tabanan Dalam Angka 2018. BPS Kabupaten Tabanan.

Bapedal. 1999. Norma dan Program Danau Lestari. Dati I Bali. Denpasar Bapedal.

Soerwarno, 2000. Hidrologi Operasional. Bandung: PT. Citra Aditya Bakti

Warren Viessmen, Jr. et all. 1972. Introduction to Hidrology. New York: Intex Educational.

Yudi Wisnawa, 2005. Studi Imbangan Air DAS Ayung. Laporan penelitian (tidak dipublikasikan). IKIP Negeri Singaraja. 